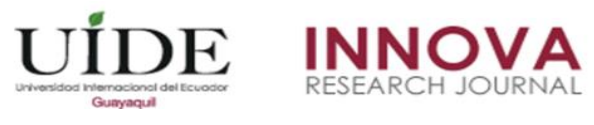

INNOVA Research Journal, ISSN 2477-9024

(Noviembre, 2018). Vol. 3, No.11 pp. 1-15

DOI: https://doi.org/10.33890/innova.v3.n11.2018.924

URL: http://revistas.uide.edu.ec/index.php/innova/index

Correo: innova@uide.edu.ec

\title{
Estudio sobre el acceso y protección de la información (GIS) y documentos confidenciales
}

\section{Study on access and protection of information (GIS) and confidential documents}

\author{
Abel Polivio Remache Coyago \\ Universidad Central del Ecuador, Ecuador \\ Edwin Giovanny Puente Moromenacho \\ Marco Vinicio Noroña Merchán \\ Daniela Alexandra Jerez Mayorga \\ Universidad Internacional del Ecuador, Ecuador \\ Autor para correspondencia: abelbelo@ hotmail.com, epuente@uide.edu.ec, \\ manoroname@uide.edu.ec \\ Fecha de recepción: 30 de agosto de 2018 - Fecha de aceptación: 01 noviembre de 2018
}

Resumen: Este artículo realiza un breve análisis referido al acceso a la información, la cual ha sido promovida por varios organismos internacionales de Derechos Humanos, para garantiza los derechos a la libertad de expresión el cual tiene un rol protagónico en el proceso democratizador, ya que permite que las personas conozcan el desempeño de las entidades públicas, fomentando la rendición de cuentas por parte de los funcionarios públicos sobre las decisiones que toman y con ello, una fiscalización ciudadana de la gestión pública. El acceso a la información es derecho que de cierta manera pasa a ser el corazón de la democracia, ya una ciudadanía que está bien informada sobre las intenciones y acciones de sus líderes electos, puede contribuir de forma efectiva al proceso de toma de decisiones que afecta su futuro. En el sentido más básico, la participación democrática depende de la habilidad de los ciudadanos de acceder a la información que necesitan para tomar el control dentro de la sociedad. Cabe indicar que también existen restricciones, normas, leyes y reglamentos para el buen acceso de la información, la misma que debe ser protegida y resguardada tanto en el ámbito nacional como internacional.

Palabras Clave: protección de la información; documentos confidenciales; mercado; interculturalidad; estados

Abstract: This paper makes a brief analysis based on the access to information, which has been promoted by several international human rights organizations, to guarantee the rights to freedom of expression which has a leading role in the democratization process, as it allows people know the performance of public institutions, promoting accountability by government officials on the decisions and thus a citizen oversight of public administration. Access to information is a right that in a certain way becomes the heart of democracy, and a citizenry that is well informed about the intentions and actions of its elected leaders, can contribute effectively to the decision-making process that affects your future. In the most basic sense, democratic participation depends on the ability of citizens to access the information they need to take control within society.It is noted that there are restrictions, rules, laws and regulations for the proper access to information, it must be protected and safeguarded at both national and international levels.

Key words: protection of information; confidential documents; market; interculturality; states 


\section{Introducción}

El derecho a la información, si se implementa correctamente, permite un diálogo entre el público y sus gobernantes, cultiva la buena gobernanza y promueve la rendición de cuentas al empoderar a los ciudadanos, los periodistas y la sociedad civil en general con la información que requieren para luchar contra la corrupción y actuar como vigilantes contra abusos por parte de las autoridades. (Mendel, 2008)

De manera más general, democratizar el acceso a la información, en particular la información en manos de entidades públicas, fomenta un clima político de apertura, transparencia y participación, que es la base de una democracia legítima. El concepto del derecho a la información se basa en que las autoridades son simplemente los guardianes de esta para la sociedad, y que la información que está en manos del Estado es también propiedad de la sociedad. Cuando la transparencia reemplaza los secretos y el poder se expone al escrutinio público, los abusos se pueden frenar, la opinión pública se puede incorporar, y el Estado puede rendirle cuentas al interés público. Todos los países del mundo necesitan un sistema de equilibrio a la toma de decisiones en el ejercicio del poder público, particularmente mediante el derecho a la información y la supervisión pública. El acceso a la información es un derecho promovido por los Derechos Humanos de las Naciones Unidas, al igual que otras entidades a nivel Internacional. Como derecho también es un deber de todas las personas saber guardar, proteger, respaldar toda la información que tiene disponible, además saber respetar las restricciones de la misma.

\section{Antecedentes}

Todas la Leyes de Transparencia y Acceso a la Información Pública tiene su origen en la Convención Interamericana de Derechos Humanos y en el Pacto Internacional de Derechos Civiles Y Políticos, tratados suscritos en 1969 y 1976, respectivamente, se refieren a los derechos inherentes e inalienables que tienen los seres humanos, catalogados como garantías, que comprometen a los estados parte a cumplir con lo suscrito en ellos. Bajo estas premisas, ambos tratados contemplan el derecho a la libertad de expresión y apelan a la creación de normativas legales, en cada país, para que garanticen el respeto y cumplimiento de éste y otros derechos.

Es así como a partir de este período, varios países de nuestra región aprobaron leyes para promover la transparencia. Actualmente Argentina, México, Perú, Colombia, Panamá, Belice, Jamaica, Trinidad y Tobago, República Dominicana y Ecuador, son algunos de los países que cuentan con esta normativa jurídica. En nuestro país se implementó la norma jurídica correspondiente que protege el derecho a acceder a la información pública, en acato a los tratados internacionales antes mencionados, de los cuales Ecuador es parte.

\section{Materiales y Métodos}

\section{Acceso a la información}

El derecho a acceder a la información que guardan las instituciones gubernamentales es usualmente percibido como un instrumento para promover la participación política. Uno de los argumentos a favor del acceso a la información es que éste es necesario para garantizar los 
derechos a la libertad de opinión y expresión que promueven la Declaración Universal de los Derechos Humanos de las Naciones Unidas así como otras declaraciones de derechos humanos y la mayoría de las constituciones nacionales. (Roberts, 2002)

Cabe indicar que la información es considerada muy importante, es así que en una Asamblea General de las Naciones Unidas, en el años 2002, en el literal e, inciso ii manifiesta: "Recibir ayuda para utilizar de manera efectiva las tecnologías de la información con miras a estimular la producción, la salvaguardia y la difusión de contenidos diversificados en los medios de comunicación y las redes de información mundiales" (ONU, Resolución 57/249, 2002)

La información no es una necesidad solamente para la gente, es una parte esencial de la buena forma de gobierno de corporaciones y de estados. Compañías débiles y gobiernos malos dependen del secreto para sobrevivir.

El secreto permite que prosperen la ineficiencia, la corrupción y el derroche. En cuanto a la esfera gubernamental, el acceso a la información permite a la gente examinar las acciones de su gobierno y constituye una base necesaria para el debate informado sobre esas acciones. Para el sector privado, el acceso a información de calidad es vital para licitaciones, para la competencia libre y para la creación de un mercado eficaz de ideas y productos. (Calland, 2002)

\section{La doctrina del derecho a la información}

Puede afirmarse que el artículo 19 de la Declaración Universal de Derechos Humanos de 1948 proclamó, por primera vez en la historia, que todo hombre tiene derecho a la información, y catalogó esta declaración como el Acta de Nacimiento del Derecho a la Información. Otros autores señalan que la libertad de información y el derecho a la información están íntimamente relacionados y que dicha libertad viene a constituir el resultado de todos los principios tradicionales de libertad de pensamiento, de expresión y de prensa, aplicados a los modernos medios de comunicación sonoros y audiovisuales.

Al contenido que involucra la libertad de información le corresponden dos aspectos que se complementan entre sí: el primero es la libertad de informar, es decir, de difundir el mensaje informativo, comprendiendo tanto la difusión del mensaje como su contenido. El otro aspecto consiste en estar bien informado, es decir, recibir sin ningún impedimento los mensajes informativos. En este sentido, la noción del derecho a la información constituye, en cierta medida, la prolongación de la libertad de información.

\section{La doctrina del derecho a la comunicación}

A partir de 1990, la comunicación del pensamiento y de las opiniones se ha visto afectada por una doble evolución. Por un lado, el vertiginoso e incesante crecimiento de la prensa, la radio y la televisión, los cuales son constantemente puestos en cuestionamiento por lo que hacen, por lo que no hacen, por lo que dicen o por lo que no dicen. Por otro lado, el surgimiento progresivo de nuevos medios que ofrecen posibilidades inéditas a la expresión de la comunicación del pensamiento, como sucede con Internet.

En este sentido, la libertad de expresión está redefinida más allá de la libertad de información, como la libertad de comunicación o derecho a la comunicación. El derecho a la 
comunicación se nos presenta como un derecho particular que le impone al Estado intervenir, según las reglas que garanticen su neutralidad, en el sentido de una mayor multiplicidad de medios, diversidad y pluralidad, y con la mayor accesibilidad a los diferentes públicos.

Esta nueva concepción, en lugar de fortalecer cualquier censura o intervención gubernamental, persigue fortalecer los medios de comunicación con trayectoria seria y responsable, así como también a los periodistas y comunicadores sociales, que se convierten en los principales garantes de la libertad, fluidez y abundancia de las ideas y pensamientos. Dicha multiplicidad y fluidez garantiza, a su vez, la necesaria confrontación pacífica que debe existir en materia de información y de ideas, que es la única vía democrática para conducirnos a la veracidad de la información. (Fuenmayor, 2004)

\section{Regulación}

De acuerdo con el Convenio, es un documento público toda información registrada en cualquier forma, elaborada o recibida por una autoridad y que esté en su poder. El Convenio determina unos mínimos que los estados miembros que se adhieran deben respetar en la regulación del derecho de acceso a la información pública. A continuación, se destacan los aspectos más relevantes de su contenido:

- Garantía del derecho de cualquiera, sin discriminación de ningún tipo y sin tener que acreditar ningún interés particular, a acceder a los documentos públicos en posesión de las autoridades públicas, habiendo definido previamente ambas categorías.

- Garantía de que las solicitudes de acceso y el acceso a la documentación no tengan ningún coste, si bien puede repercutirse en la persona solicitante el coste que genera el servicio o la obtención de copias.

- Posibilidad de establecer una lista limitada de excepciones (art. 3.1), sujetas a criterios de interés público, siempre y cuando estos límites estén previstos por una ley, sean necesarios en una sociedad democrática y proporcional a la finalidad de proteger otros derechos o intereses legítimos.

- En línea con lo previsto por gran parte de las normas de los estados miembros del Consejo de Europa, el Convenio también ha establecido que hay que aplicar los principios de daño efectivo y de interés público preferente en el acceso, antes de denegar el acceso en base a la aplicación de alguna de las excepciones que enumera el artículo 3.1 del Convenio. Eso significa que para el supuesto de que pueda darse una de las excepciones al acceso que prevé el Convenio, la Administración debe valorar si el acceso provocaría un daño real al derecho o el interés protegido con la excepción y ponderar si se da un interés público superior en la difusión, en relación con la afectación del derecho o el interés protegido con la excepción. Esta valoración debe hacerse caso por caso y partiendo del principio de que el acceso debe ser la regla, y el rechazo de la difusión la excepción.

- En cuanto al procedimiento de tramitación de las peticiones de acceso, cabe destacar que, a pesar de que el Memorándum explicativo del Convenio elaborado por el propio Consejo (Explanatory Report) establece que una respuesta ágil y rápida es parte esencial del contenido del derecho de acceso a la información pública, no fija ningún plazo concreto de respuesta.

- La denegación de la petición debe ser motivada y debe garantizarse el derecho de las personas solicitantes a un procedimiento de recurso o revisión de esta decisión, previo al 
acceso a los tribunales de justicia o a una entidad independiente e imparcial. (Síndic de Greuges de Catalunya, 2012)

Las normas internacionales y las buenas prácticas ya están bien establecidas. Existen estudios comparativos de las legislaciones (por ejemplo, el de Toby Mendel sobre el derecho de acceso a la información en América Latina de 2009) pero hay muy pocos sobre las prácticas. El Centre for Law and Democracy y Access Info, las ONG que han lanzado la campaña de ratificación de la Convención del Consejo de Europa, han difundido en 2010 un instrumento de evaluación de las legislaciones sobre el DAI.

Este instrumento distingue siete ámbitos cubiertos por las leyes de acceso. Los principales elementos del marco normativo pueden reagruparse en:

1. El derecho de acceso: debe ser garantizado por la Constitución de modo preciso. Las referencias a los grandes principios no bastan. El principio de divulgación máxima debe ser afirmado por la ley.

2. El campo de aplicación: los beneficiarios, los documentos sobre todo tipo de soporte, el acceso a los documentos y a la información, el sector público (las tres ramas, legislativa, ejecutiva y judiciaria), el sector privado (las empresas que desempeñan un papel público o reciben financiaciones públicas) y la publicación proactiva de las informaciones. (www.ala-archivos.org, 2011)

\section{Medidas de acompañamiento para su aplicación efectiva}

Las medidas de acompañamiento imprescindibles no suelen figurar en la ley. Se necesitan primero medios financieros, humanos y materiales (equipamientos informáticos y fotocopiadores) concedidos a las administraciones à las que se imponen nuevas tareas. La guía de aplicación del modelo de ley interamericana de la Organización de los Estados Americanos facilita las líneas presupuestarias que conviene contemplar.

Conviene también tomar de manera simultánea diferentes medidas:

1. Designación de los responsables de la aplicación de la ley: sus nombres y coordenadas deben figurar en los sitios web de las administraciones.

2. Establecimiento de programas de formación de funcionarios: la formación inicial y continua de quienes tienen a su cargo la aplicación de la ley constituye una prioridad, y es una función transversal que toca a mucha gente.

3. Creación de un organismo responsable de la promoción del derecho a la información así como de la sensibilización du público: suele ser el organismo que instruye los recursos Comisaría para la información, CADA, IFAI. Su misión consiste a la vez en informar de sus derechos al público en general y en prestar ayuda a los organismos públicos para que cumplan su obligación en este particular.

4. normas mínimas de gestión de documentos: la efectividad de la ley depende mucho de la calidad de la gestión de los documentos y de los datos. Suele ser a menudo un obstáculo, porque las administraciones consideran que se trata de una tarea secundaria y no saben qué es lo que conservan. Pues bien: para poder contestar rápidamente a una demanda de información, es preciso saber si existe, así como localizarla y encontrarla. (Canavaggio, 2011) 


\section{Diversidad cultural}

Según algunos autores, los mundos culturales se originan en la globalización y se construyen como multiculturalidad por migraciones y, en general, por la movilidad de los grupos de población.

La multiculturalidad tiene sus raíces en el origen de cada uno de los pueblos del mundo, con sus creaciones propias, sus tradiciones y sus formas de organización. Este tipo de análisis lleva a la observación no sólo de las creaciones propias de un grupo humano, sino también de las condiciones sociales, favorables o no, para crear y vivir en la multiculturalidad.

Una forma más avanzada de la integración de las culturas es la interculturalidad y se refiere al encuentro de culturas diversas para observarse, entenderse mutuamente y conocerse cada vez mejor. Ese encuentro cultural está relacionado con la armonización de las relaciones humanas, lo que permite pensar que este entendimiento supone una evolución de las sociedades en el terreno de la comprensión y de la empatía.

La interculturalidad permite reflejar la dinámica social y formular el objetivo de nuevas síntesis socioculturales. La información en fenómenos de diversidad cultural debe entenderse en dos sentidos: en primer lugar, como aquella dirigida a los individuos que se insertan en culturas diferentes a la propia y tiene como objetivo permitir que conozcan las características, ventajas y problemas que tiene el grupo social al que habrán de pertenecer, pero también sirve para proporcionarles materiales de lectura e información acerca de su propio país o región de origen, con el objeto de evitar el olvido y mitigar el dolor del desarraigo que siempre existe y, además y no pocas veces, las vivencias de un rechazo inicial en la nueva situación. (Morales, 2008)

La información en fenómenos de diversidad cultural debe entenderse en dos sentidos: en primer lugar, como aquella dirigida a los individuos que se insertan en culturas diferentes a la propia y tiene como objetivo permitir que conozcan las características, ventajas y problemas que tiene el grupo social al que habrán de pertenecer, pero también sirve para proporcionarles materiales de lectura e información acerca de su propio país o región de origen, con el objeto de evitar el olvido y mitigar el dolor del desarraigo que siempre existe y, además y no pocas veces, las vivencias de un rechazo inicial en la nueva situación.

La diversidad cultural se ha hecho más relevante en la actualidad en razón del desarrollo de los medios de comunicación y del aumento de las posibilidades de movilización que hoy existen, al punto de que la UNESCO, en 2001, emitió la Declaración Universal de la Diversidad Cultural donde la califica como patrimonio común de la humanidad. En esta Declaración destacan la necesidad de garantizar la interacción armoniosa y la convivencia de las personas y de los grupos así como las políticas que favorecen estas instancias. (UNESCO, 2001)

\section{Tolerancia, políticas culturales y sociales, y multiculturalismo}

El fenómeno del multiculturalismo, en la actualidad, puede hacer a las naciones presa fácil del caos. Es un proceso que representa un problema social por la mezcla de diversos elementos sociales interrelacionados entre sí; factores como, por ejemplo, política, educación y el mismo Estado. En suma, la falta de unas políticas públicas, sociales, culturales y educativas se 
conjuga con la indefinición de las mismas, y con una falta de visión en su planeación y un inadecuado diseño en su instrumentación.

El establecimiento de políticas, planes o programas debe contar con un sentido humanístico, que sirva como catalizador en pro de la integración de los diversos grupos en una sociedad plural, motivando una integración nacional tanto en lo cultural como en lo social. En la actualidad, las naciones se reorganizan constantemente por la gran movilidad que se ha generado a escala local, regional e internacional, por diversas razones de índole económica, social o política, generando nuevas demandas y servicios.

El nuevo orden social emergente se encuentra en constante crecimiento, y se hace más complejo al adicionarse factores económicos, religiosos, ideológicos, de género, étnicos, laborales, sexuales, etcétera; en conjunto, éstos generan movimientos en la población que demanda más y nuevos servicios, piden espacios acordes a los perfiles de interés de las personas pertenecientes a grupos que tienen la necesidad creciente de una representatividad en el orden social; además, desean sentirse parte del desarrollo social de la nación, tomar decisiones dentro de la sociedad a la cual pertenecen sin perder su identidad de origen. (Hernández, 2008)

Actualmente se requiere contar con espacios y con instituciones en manos de profesionales que apoyen y fomenten accesos a la información y que deseen tener disponible o resguardar el valor cultural del contenido para los grupos que surgen por el multiculturalismo. En cierta forma hay una demanda de sistemas que facilitan la información necesaria para asimilar en los grupos el proceso de integración, de una manera democrática, de la nueva cultura emergente, buscando preservar la cultura de origen. El término multiculturalismo tiene varias formas de definirse, lo que genera distintas acepciones del concepto.

Existen algunas acepciones sobre perspectivas del multiculturalismo en diversos entornos y contextos que se van interrelacionando en la sociedad actual; así tenemos:

- Lo social invita a los distintos grupos culturales a tomar conciencia de la diversidad cultural existente, representada por identidades propias en los distintos ámbitos, tales como grupos religiosos, nacionales y étnicos, con el objetivo de lograr una convivencia positiva y no violenta.

- Lo económico se basa en la "globalización" a un nivel consumista y productivo, con formas de identidad cada vez menos sociales.

- El enfoque epistemológico reconoce al lenguaje y los discursos que transmite cada cultura como la manera en que se nos transmite lo extraño junto a lo diverso de lo extranjero.

- La educación tiene como objetivo una reflexión crítica de todos los elementos, como las creencias, los valores y los prejuicios culturales que permiten las relaciones interculturales.

- La ética-política propone una convivencia ética multicultural, teniendo como fundamento el reconocimiento y la aceptación de las otras culturas, y a la vez renunciando a todo aquello que conlleve al poder y a la dominación.

\section{Desafíos profesionales de los servicios de información}


Al no atender estas nuevas formas de organización de la sociedad, se ha presentado un problema que se refleja en la falta de oportunidades, acentuado por la desigualdad económica. Los grupos generan y demandan derechos en varios sentidos, entre los que destaca el derecho a la información, que posiblemente sea el más importante.

La información es el insumo primordial en la sociedad moderna por su incidencia en un alto desarrollo económico, social, científico y tecnológico; se constituye en la piedra angular para cualquier nación que desea integrarse a un mundo globalizado; es una demanda de crear accesos a la información cultural, científica y tecnológica, que permita a las naciones y a la sociedad en su conjunto tener la oportunidad de mejorar y elevar estándares de vida, ayudando a ser más competitivos en la generación de conocimiento con productos de calidad que permitan una mayor interacción.

Las políticas deben ser una alternativa que permita garantizar a las personas o grupos preservar su identidad cultural, al mismo tiempo que se otorgue una forma de motivación sutil que sirva para integrarlos a la sociedad que los acoge, preservando sus garantías de grupo y respetando sus derechos e intereses.

Todos, al ser parte de una nación, tendremos al mismo tiempo el compromiso de asimilar, acatar y respetar ciertas obligaciones. Podemos decir que la libertad de expresión y el acceso a la información son medulares en la construcción de un "criterio público", capaz de fortalecer el desarrollo de una relación más democrática entre los miembros de la sociedad, instituciones públicas, procesos políticos y sociales. (Yankelovich, 1995)

La interacción entre lo global, lo regional, lo nacional o lo local nos exige técnicas de comunicación, información y acceso al conocimiento basadas en nuevas tecnologías, factores que nos obligan a diferenciar y a tener presentes los nuevos códigos culturales que se desarrollan; tenemos que estar conscientes de que el concepto de cultura se modifica y aumenta en las nuevas condiciones del sistema global.

Como estímulo, según Gutiérrez es necesaria la construcción de identidades sociales asentadas en el aprecio de la tolerancia, el respeto a la legalidad y la corresponsabilidad, fomentando la participación ciudadana informada, para lograr el rechazo a la discriminación y a la violación de los derechos humanos. Los puntos mencionados son indispensables para un proceso cultural, articulando una relación entre sociedad e instituciones de forma equilibrada y con responsabilidad de ambas partes. (Gutiérrez, 2005)

Si un sistema, desde el punto de vista social, niega el acceso a la información, el usuario lo convertirá en solamente un receptor de beneficios; no tendrá capacidad para generar cambios ni iniciativa en el desarrollo de una sociedad más democrática; empero, por el contrario, sí puede convertirse en un riesgo enorme para la estabilidad social y nacional, dependiendo de su capacidad de interacción y de organización con grupos afines o de interés específico, pues buscará ser escuchado y tomado en cuenta por la sociedad.

Según Peter Drucker, los desafíos de información para ser más competitivos en un mundo globalizado, lo destaca en: 
- Información fundamental de caja, liquidez, bonos.

- Información de productividad comparando desempeño propio versus industria.

- Información de habilidades a través de la innovación.

- Información para asignación de recursos escasos como capital y personal. (Drucker, 2002)

Parece existir un consenso creciente sobre la necesidad de adaptar los marcos éticos y normativos, existentes en materia de propiedad intelectual, a las circunstancias de la globalización de las redes de información, de la integración de diferentes medios de comunicación, y de la diversidad creciente de aplicaciones de las nuevas tecnologías. Las actividades económicas han experimentado y seguirán realizando cambios radicales.

Una parte cada vez más sustantiva del trabajo se realiza ya fuera de las oficinas y las fábricas, desde los ambientes más diversos, incluyendo algunos que hasta hace poco tiempo estaban reservados, de manera exclusiva, a la convivencia social y familiar. La aplicación de las nuevas tecnologías no sólo determina una transformación concreta de los alcances y límites de nuestra percepción y valoración del mundo; también afecta la conciencia de nuestra identidad y la expresión de nuestra interioridad. El reconocimiento de nuestra identidad, como personas y como miembros de determinados grupos sociales, depende cada vez más de su expresión en el espacio cibernético. Nuestra personalidad adquiere, de esta manera, nuevas formas de identidad y manifestación, que son independientes de nuestra conciencia personal. (Montero, 2002)

La formación moral deberá ser asumida con un sentido renovado de responsabilidad y urgencia por las instituciones educativas, reconociendo que la misma forma parte del esfuerzo para afirmar la vivencia de los valores democráticos, y asumiendo que todavía en la mayoría de los países la comprensión que tienen los jóvenes de esos valores es sólo superficial; que el conocimiento y compresión de los mismos y la medida en que las instituciones educativas facilitan su vivencia es un factor determinante de su puesta en práctica; que, en general, la juventud mantiene una actitud positiva hacia la participación y el compromiso social; que los medios de información, y en especial la televisión, determinan en gran medida el contenido y la orientación de las opiniones de la juventud; y que los educadores suelen manifestar opiniones favorables hacia el desarrollo moral. (IEA, 2001)

\section{Protección de la información}

\section{Resultados}

La información es, hoy en día, la moneda de las organizaciones. Bases de datos, repositorios de documentos, aplicaciones para compartir archivos, sistemas de archivos de usuarios finales y dispositivos de almacenamiento portátiles son los lugares en los que se almacena y desde los que se accede a la información. Se intercambia dentro de la organización y se comparte con distribuidores, socios comerciales, usuarios finales, consumidores, instancias gubernamentales y muchos otros agentes externos. A menudo, esta información se almacena, utiliza e intercambia de manera inadecuada.

Además, cada día es objetivo de más ataques y robos. No proteger la información puede traducirse en el incumplimiento de normativas, multas, pleitos, pérdidas de ventajas competitivas, daños en la imagen de marca e incluso violaciones de la seguridad nacional. La 
proliferación de aplicaciones basadas en web y del intercambio de información agravan estos riesgos. La respuesta actual: Las herramientas tradicionales de prevención de fugas de información se fundamentan en controles simplistas de "encender y apagar" basadas en tecnologías primitivas de identificación de la información.

Las soluciones de seguridad deben trasladar el objetivo básico de la protección de evitar que las infraestructuras sufran ataques del exterior para proteger la información esencial de posibles filtraciones. La información, como uno de los principales activos de las organizaciones, debe protegerse a través de la implantación, mantenimiento y mejora de las medidas de seguridad para que cualquier empresa logre sus objetivos de negocio, garantice el cumplimiento legal, de prestigio y de imagen de la compañía.

La seguridad de la información, según ISO 27001, consiste en la preservación de su confidencialidad, integridad y disponibilidad, así como de los sistemas implicados en su tratamiento, dentro de una organización.

Para garantizar que la seguridad de la información es gestionada correctamente se debe identificar inicialmente su ciclo de vida y los aspectos relevantes adoptados para garantizar su CI-D:

- Confidencialidad: la información no se pone a disposición ni se revela a individuos, entidades o procesos no autorizados.

- Integridad: mantenimiento de la exactitud y completitud de la información y sus métodos de proceso.

- Disponibilidad: acceso y utilización de la información y los sistemas de tratamiento de la misma por parte de los individuos, entidades o procesos autorizados cuando lo requieran.

En base al conocimiento del ciclo de vida de cada información relevante se debe adoptar el uso de un proceso sistemático, documentado y conocido por toda la organización, desde un enfoque de riesgo empresarial. Este proceso es el que constituye un "Sistema de Gestión de la Seguridad de la Información” SGSI. (ISO, 2005)

De acuerdo algunos autores la piedra angular del Sistema de Gestión ISO 27001 es el análisis y gestión de los riesgos basados en los procesos de negocios y servicios (Fernández, 2012)

La primera expresión de protección tangible que se brinda a la información es la que se encuentra en artículo 23 numeral 13 la Constitución Política del Estado: "La inviolabilidad y el secreto de la correspondencia. Esta sólo podrá ser retenida, abierta y examinada en los casos previstos en la ley. Se guardará el secreto de los asuntos ajenos al hecho que motive su examen. El mismo principio se observará a cualquier otro tipo de forma de comunicación." (Jaramillo, 2008)

El concepto de seguridad de la información no debe ser confundido con el de seguridad informática, ya que este último sólo se encarga de la seguridad en el medio informático, pero la información puede encontrarse en diferentes medios o formas, y no solo en medios informáticos. Para el hombre como individuo, la seguridad de la información tiene un efecto significativo 
respecto a su privacidad, la que puede cobrar distintas dimensiones dependiendo de la cultura del mismo.

El campo de la seguridad de la información ha crecido y evolucionado considerablemente a partir de la Segunda Guerra Mundial, convirtiéndose en una carrera acreditada a nivel mundial. Este campo ofrece muchas áreas de especialización, incluidos la auditoría de sistemas de información, planificación de la continuidad del negocio, ciencia forense digital y administración de sistemas de gestión de seguridad, entre otros.

De acuerdo a nuestra constitución "la divulgación o la utilización fraudulenta de la información protegida, así como de los secretos comerciales o industriales, será sancionada con pena de reclusión menor ordinaria de tres a seis años" (Jaramillo, 2008)

Frente a revelaciones, modificaciones o destrucciones de la información, es muy importante la protección contra amenazas de confidencialidad, integridad y disponibilidad, siendo fallos de organización, humanos, técnicos o actos mal intencionados.

Al hablar de protección de información no se trata solo de la Seguridad de información, la misma que suministra protección ante accesos no autorizados, daños e interferencias en instalaciones de la organización, sino también de la seguridad física, considerada como la protección ante accesos no autorizados, daños e interferencias a las instalaciones de la organización, proteger el área y las redes de comunicación. (Rivas, 2003)

\section{Características de un régimen de derecho a la información}

El derecho a la información permite algunas restricciones. El Artículo 19(3) del ICCPR estipula: El ejercicio del derecho previsto en el párrafo 2 de este artículo [el derecho a libertad de expresión] entraña deberes y responsabilidades especiales. Por consiguiente, puede estar sujeto a ciertas restricciones, que deberán, sin embargo, estar expresamente fijadas por la ley y ser necesarias para: Asegurar el respeto a los derechos o a la reputación de los demás;

La protección de la seguridad nacional, el orden público o la salud o la moral públicas. Se reconocen reglas similares para las restricciones en los tratados regionales sobre los derechos humanos y en muchas constituciones nacionales. De conformidad con esta disposición, las restricciones deben cumplir con una estricta prueba compuesta de tres partes (ONU, Pacto Internacional de Derechos Políticos, 1976).

De acuerdo a los Derechos Humanos y a las jurisprudencias internacionales se dispone que cualquier restricción del derecho a la información deberá disponerse por vía legal. Las restricciones que no tengan fundamento legal, como por ejemplo un simple ejercicio de la discreción administrativa, no son legítimas. Este requisito se cumplirá únicamente cuando la ley en cuestión sea accesible.

Las reglas indebidamente vagas, o las reglas que permitan una excesiva discreción en su aplicación, no cumplen con estos requisitos. La restricción debe tener una finalidad legítima, entre las enumeradas en el Artículo 19(3) del ICCPR. Esta lista es exhaustiva, aunque sea bastante amplia, de modo que las restricciones con otras finalidades, por ejemplo para evitar una 
situación vergonzosa para el Gobierno, no son legítimas. (ONU, Pacto Internacional de Derechos Políticos, 1976)

\section{Transparencia máxima}

La legislación sobre la libertad de información debe guiarse por el principio de la transparencia máxima, el cual se podrá derivarse de las garantías primarias del derecho a la información y encapsula el significado central del derecho a la información. Una versión de esto se expresa explícitamente como objetivo de varias leyes nacionales. El principio de la transparencia máxima implica que el alcance del derecho a la información debe ser tan amplio como la gama de información y entidades respectivas, así como los individuos que puedan reclamar el derecho. A nivel muy general, el Principio 2 de la Mancomunidad dice: "Debe haber una inclinación a favor de la divulgación”. (Mendel, 2008)

El Principio 1 del CJI también declara que: "En principio, toda la información debe ser accesible." También insiste claramente que el acceso es un derecho humano fundamental, lo cual es un fundamento importante para la presunción de divulgación.

La Declaración Conjunta de los mandatos especiales sobre la libertad de expresión contiene una declaración fuerte y explícita sobre la transparencia máxima: El derecho de acceder a la información que está en manos de autoridades públicas es un derecho humano fundamental que debe darse vigencia a nivel nacional mediante legislación integral en el caso de la libertad de información, en base al principio de transparencia máxima, estableciendo la suposición de que toda información está accesible, con sujeción apenas a un sistema escueto de excepciones. Más específicamente, las Normas de la ONU anotan: "Las entidades públicas tienen la obligación de divulgar información y cada miembro del público tiene el correspondiente derecho de recibir información; la 'información' incluye todos los registros que estén en manos de alguna entidad pública, independiente a la forma en que estén almacenados”.

La Convención de Aarhus también define la información muy ampliamente, para incluir "cualquier información en forma escrita, visual, auditiva, electrónica o en cualquier otra forma material", aunque su alcance, de conformidad con su propósito, está limitado a la información ambiental (Artículo 2(3)). La Recomendación COE es más cautelosa, definiendo los 'documentos oficiales' ampliamente como "toda la información registrada en cualquier forma, elaborada o recibida por y en manos de las autoridades públicas" pero limita su alcance a la información vinculada con "cualquier función pública o administrativa" y excluye los documentos que estén elaborándose.

En la práctica, la mayoría de las leyes nacionales sí definen la información bastante ampliamente, mientras que una minoría restringe el alcance de la información cubierta, en base a la forma en que se use la información. (ONU, Pacto Internacional de Derechos Políticos, 1976)

\section{Obligación de publicar}

Las entidades públicas deben tener la obligación de publicar la información clave. Para dar vigencia en la práctica al derecho a la información, no es suficiente simplemente requerir que las entidades públicas accedan a las solicitudes de información. Un acceso efectivo para muchas 
personas depende de que estas entidades publiquen y difundan activamente categorías clave de información aun en ausencia de alguna solicitud.

Esto se refleja en varias declaraciones internacionales. Por ejemplo, las Normas de la ONU dicen: La libertad de información implica que las entidades públicas publiquen y difundan ampliamente documentos de significativo interés público, por ejemplo, información operativa sobre cómo funciona la entidad pública y el contenido de cualquier decisión o política que afecte al público (IFEX, 2010)

\section{La lucha contra la corrupción}

Se ha reconocido ampliamente la necesidad de acceder a la información que está en manos de las entidades públicas como herramienta para ayudar a enfrentar el muy grave y difícil problema de luchar contra la corrupción. En 2003, la publicación anual de la Transparencia Internacional, su Informe Mundial sobre la Corrupción, incluyó un enfoque especial en el acceso a la información, resaltando su importancia para combatir la corrupción. En la introducción al informe, Eigen anota que el acceso a la información es "posiblemente el arma más importante contra la corrupción." (Prolife, 2003)

Esto ahora se expresa formalmente en la Convención Contra la Corrupción de la ONU. La Convención está repleta de referencias a la transparencia y apertura. Significativamente, sus disposiciones sobre la participación pública son casi totalmente dedicadas a cuestiones de la transparencia e información.

El Artículo 10 de la Convención dispone que cada Estado, adoptará las medidas que sean necesarias para aumentar la transparencia en su administración pública. Esas medidas podrán incluir, entre otras cosas:

a) La instauración de procedimientos o reglamentaciones que permitan al público en general obtener, cuando proceda, información sobre la organización, el funcionamiento y los procesos de adopción de decisiones de su administración pública y, con el debido respeto a la protección de la intimidad y de los datos personales, sobre las decisiones y actos jurídicos que incumban al público. (ONU, Asamblea General, 2005).

\section{Costos}

No se debe impedir que los individuos soliciten la información mediante costos excesivos. El cobro de tarifas por el acceso a la información es otro asunto difícil. Por un lado, si son excesivas las tarifas, constituirán una barrera al acceso, lo que perjudicará el derecho. Por otro lado, sí tiene sus costos para las entidades públicas prestar los servicios de permitir acceso, y deberían tener alguna manera de recuperar estos costos.

Varias declaraciones internacionales sobre el derecho a la información tocan este tema. Por ejemplo, las Normas de la ONU anotan que el costo de acceso "no debe ser tan alto que desmotive a potenciales solicitantes, negando la intención de la misma ley". El Principio 5 del CJI, mencionado anteriormente, pide que el acceso sea "gratuito o de bajo costo". El Principio VII de la Recomendación COE es más específico, exigiendo que sea gratuito consultar los documentos y que los cobros por copias no excedan de los costos realmente incurridos. 
La Convención de Aarhus tiene reglas razonablemente detalladas sobre las tarifas; su Artículo 4(8) dice: Cada Parte podrá autorizar a las autoridades públicas que faciliten informaciones a percibir un derecho por este servicio, pero ese derecho no deberá exceder de una cuantía razonable. (ECE, 1999)

Las autoridades públicas que tengan la intención de imponer el pago de un derecho por las informaciones que faciliten comunicarán a los solicitantes de información las tarifas de los derechos que hayan de pagarse, indicando los casos en que las autoridades pueden renunciar a la percepción de esos derechos y los casos en que la comunicación de informaciones está sujeta a su pago anticipado. En la práctica, hay una amplia variabilidad en la forma en que los diferentes países abordan la cuestión de las tarifas por el acceso a la información. (Mendel, 2008)

\section{Conclusiones}

El acceso a la información es considerado como uno de los derechos más importantes no solo para el Estado sino también para todas las personas que lo conforman, considerado como el corazón de la democracia. Mediante la Declaración Universal de los Derechos Humanos de las Naciones Unidas, así como otras declaraciones de derechos humanos y la mayoría de las constituciones consideran que el acceso a la información es un instrumento para promover la participación política. Se puede observar que la información es necesaria para garantizar los derechos a la libertad de opinión y expresión a nivel nacional como internacional.

Como un derecho el acceso a la información también tiene sus restricciones, pues asegura el respeto a los derechos o a la reputación de los demás, la protección de la seguridad nacional, el orden público. Emitiendo reglas para las restricciones en los tratados regionales sobre los derechos humanos y en muchas constituciones nacionales. Si bien es cierto el acceso a la información está considerado como un arma para evitar la corrupción, ya que los datos emitidos por las entidades públicas deben ser completamente transparentes, para evitar malos entendidos, en muchos casos se la oculta o no se da a conocer completamente, con el fin de cubrir ineficiencias en ciertos sectores.

\section{Bibliografía}

Calland, R. (2002). El Acceso A La Información: ¿Para Qué Sirve? ¿Y Cómo Se Utiliza? El Acceso A La Información: La Llave Para La Democracia, 17.

Canavaggio, P. (2011). El Acceso A La Información Pública En El Mundo. $7^{\circ}$ Seminario Internacional De Archivos De Tradición Ibérica, (Págs. 10-12). Rio De Janeiro.

Drucker, P. (2002). Los Desafíos De La Gerencia. Bogotá: Editorial Norma.

Ece. (15 De Enero De 1999). Comisión De Aarhus. Obtenido De Comisión Económica Para Europa: Http://Www.Unece.Org/Fileadmin/Dam/Env/Pp/Documents/Cep43s.Pdf

Fernández, C. M. (2012). Las Normas Iso 27001 Del Sistema De Gestión De Información. Aenor, 41.

Fuenmayor, A. (2004). El Derecho De Acceso De Los Ciudadanos A La Información Pública. San José, Costa Rica: Unesco. 
Gutiérrez, D. (2005). Multiculturalismo. En D. Gutiérrez Martínez, Multiculturalismo, Desafíos Y Perspectivas. México: Siglo Xxi.

Hernández, J. (2008). Tolerancia, Políticas Culturales Y Sociales Y Multiculturalismo. En E. Morales, J. Hernández, \& M. Rosa, Diversidad Cultural Y Acceso A La Información. México: Creative Commons.

Iea. (2001). Evaluación Del Proceso Educativo. En I. D. Education, Summary of the Major Findings. Estados Unidos: Iea.

Iso, P. (2005). El Portal De Iso 27001 Español. Obtenido De Iso 27001.Es: Http://Www.Iso27000.Es/Sgsi.Html

Jaramillo, A. (2008). Legal De La Información. Revista Judicial Derechoecuador.Com.

Mendel, T. (2008). Costos De Información. En T. Mendel, El Derecho A La Información En América Latina (Pág. 48). Quito: Unesco.

Montero, I. (2002). Los Desafíos De Las Tecnologías De La Información Y De Las Comunicaciones En La Educación. España: Ocde.

Morales, E. (2008). Diversidad Cultural. En E. Morales, Diversidad Cultural Y Acceso A La Información. México D.F.: Creative Commons.

Onu. (1976). Pacto Internacional De Derechos Políticos. Obtenido De Iccpr: Http://Www.Ohchr.Org/En/Professionalinterest/Pages/Ccpr.Aspx

$\begin{array}{lllll}\text { Onu. } & \text { (2002). } & \text { Resolución } & \text { Obtenido } & \text { De }\end{array}$ Http://Www.Un.Org/Es/Comun/Docs/?Symbol=A/Res/57/249

Onu. (14 De Diciembre De 2005). Asamblea General. Obtenido De Derecho Civil Contra La Corrupción: Http://Www.Unodc.Org/Unodc/En/Treaties/Cac/Index.Html

Prolife. (2003). Transparencia Internacional. Informe Mundial Sobre Corrupción. Londres: Prolife Books.

Rivas, J. L. (2003). Protección De La Información. España: Ediciones Virtualibro.

Roberts, A. (2002). Acceso A La Información Gubernamental: Compendio De Temas. Acceso A La Información: La Llave Para La Democracia, 9-10.

Síndic De Greuges De Catalunya. (2012). El Derecho De Acceso A La Información Pública. Catalunya: Síndic De Greuges.

Unesco. (2001). Declaración Universal De La Unesco Sobre Diversidad Cultural. En Unesco. París.

Www.Ala-Archivos.Org. (2011). Archivos. Obtenido De El Acceso A La Información En El Mundo: Http://Www.Access-Info.Org/Es/Rti-Rating/111-Rti-Rating-Methodology

Yankelovich, D. (1995). Criterio Público. En D. Yankelovich, Para Alcanzar Un Criterio Público, Como Lograr Que La Declaración Funcione. (Pág. 326). México: Publigrafics 